\title{
RETRACTED ARTICLE: Importance of hypogonadism and testosterone replacement therapy in current urologic practice: a review
}

\author{
Maurizio Buscarini • Antonio Cardi
}

Received: 14 September 2009/ Accepted: 10 February 2010/Published online: 12 March 2010

(C) Springer Science+Business Media, B.V. 2010

This article has been retracted on grounds of dual publication.

This article has been retracted on grounds of dual publication.

M. Buscarini

Department of Urology, University Campus Bio-Medico,

Rome, Italy

A. Cardi $(\square)$

Department of Urology, S. Camillo Hospital, Rieti, Italy

e-mail: a.cardi@asl.rieti.it 